\title{
Respiratory findings among ironworkers: results from a clinical survey in the New York metropolitan area and identification of health hazards from asbestos in
} place at work

\author{
Alf Fischbein, Jiin-Chyuan J Luo, Stanley Rosenfeld, Margot Lacher, Albert Miller, \\ Alfred Rosenbaum
}

\begin{abstract}
Diseases associated with asbestos are prevalent in the construction trades primarily as the result of the previously widespread use of insulation materials containing asbestos in the building industry. Workers in metal related trades, who are employed at construction sites, but who do not routinely use such materials in their work, may also be at risk for asbestos hazards. To assess such risk, a clinical survey was conducted on 869 ironworkers from the New York metropolitan area. A high prevalence of abnormalities on chest radiographs was found. Three hundred and twenty nine $(38 \%)$ of the examined workers had pleural abnormalities on their chest radiographs consistent with asbestos induced effects. The prevalence of radiographic abnormalities indicating interstitial lung disease was low (7\%) as was the prevalence of restrictive pulmonary function impairment (7\%). Association was found between forced vital capacity (FVC) and pleural abnormalities on chest radiographs. Although ex-smokers appeared to have the highest prevalence of abnormalities, regression analyses showed that duration of employment in the ironworkers' trade was the most important factor associated with them.
\end{abstract}

Division of Environmental and Occupational Medicine, Department of Community Medicine, Mount Sinai School of Medicine of the City University of New York, One Gustave L Levy Place, New York, New York 10029, USA

A Fischbein, J-C J Luo, M Lacher

Department of Radiology, Mount Sinai Hospital, New York, USA

S Rosenfeld, A Rosenbaum

Pulmonary Division, Department of Medicine, The Mount Sinai Medical Center, New York, New York 10029, USA

A Miller
Asbestos related health hazards constitute a major public health problem in the United States. ${ }^{1}$ Several disorders have been shown to be related to exposure to airborne asbestos fibres. Characteristically, exposure to harmful concentrations of asbestos dust at a workplace can result in diseases that only manifest themselves clinically decades later. Therefore, most of the serious health consequences, such as lung cancer and mesothelioma, affect people now, who were employed in work environments with excessive exposure to asbestos during the 1940s and the subsequent two decades. In fact, few clinical abnormalities related to asbestos occur during the first 10 years of potential overexposure to airborne dusts containing asbestos.

Asbestos associated diseases are prevalent among workers employed in the construction trades primarily as the result of previously widespread use of insulation materials containing asbestos in the building industry. Workers of metal related trades who are employed at construction sites and power facilities but who do not routinely use such materials in their work may also be at risk for asbestos hazards because of manipulation of materials containing asbestos in place at the work site. Ironworkers, for example, are often engaged in the construction, repair, or demolition of buildings with metal structures, which, as well as a protective coating of lead based paint, are frequently covered with materials containing asbestos. The lead related hazard among the ironworkers described have been reported. ${ }^{2}$ Two ironworkers who had developed malignant pleural mesothelioma served as a health sentinal event for the present investigation.

\section{Materials and methods}

Because of concern over potential adverse health effects of long term exposure to asbestos, a clinical survey was conducted on 869 ironworkers. All were volunteers who had responded to a written communication distributed among the members of four 
local unions in the New York metropolitan area and in an adjacent county in New York State. The number of participating ironworkers represented around $30 \%$ of the total membership (active and retired workers) of the local unions at the time of the examinations. Three hundred and fifteen workers $(36.2 \%)$ belonged to a local union of structural ironworkers and $310(35.7 \%)$ were derived from a local union of ornamental ironworkers. The remaining workers were local people with both structural and ornamental workers in their membership.

The examination included review of occupational and medical histories. A comprehensive physical examination was performed with special emphasis on the cardiopulmonary systems. Respiratory histories were recorded according to a modified version of the British Medical Research Council questionnaire. Blood tests-namely, a complete blood count and biochemistry screen as well as urine analysis were done to evaluate the general health state; special immunological tests were performed on a subset of the population. ${ }^{3}$

Chest radiographs consisting of standard $36 \mathrm{~cm} \times$ $43 \mathrm{~cm}$ posteroanterior and lateral views were taken of all participants. Oblique projections were taken whenever indicated by initial review of the posteroanterior projection. The chest $x$ ray films were evaluated by both standard radiological interpretation and interpretation according to the International Labour Office international classification of radiographs of pneumoconioses, $1980 .{ }^{4}$

Pulmonary function examinations consisted of spirometry and were completed on only 527 of the 869 workers. This was because of technical and administrative difficulties and was not the result of our voluntary exclusion of workers. Spirometry was performed using a computerised pneumotachygraph (Medical Graphics model 1065). Calibration and testing adhered to the American Thoracic Society guidelines (1987); subjects were standing and wore nose clips. The predicted values of Miller et al were used. $^{5}$

The data were encoded and entered into the computer centre of the City University of New York. The data were analysed, using the statistical package for the social sciences (SPSSX) software package and the statistical analysis system (SAS) software package.

Student's $t$ test and one way analysis of variance were performed to compare mean values of pulmonary function variables for the smoking categories, chest $x$ ray film abnormalities, respiratory signs and symptoms, and duration of employment. The differences in prevalence of chest radiographic abnormalities among smoking categories stratified by duration of employment were tested for significance by $\chi^{2}$ statistics. Multivariate regression analyses were also performed to identify the best model of variables such as radiographic abnormalities, smoking state, duration of employment, respiratory signs and symptoms, and ship or shipyard related work experience to predict pulmonary function values. Logistic regression analyses gave the magnitude and significance of the effect of duration of employment on respiratory signs and symptoms and the presence of pleural abnormalities after controlling for smoking state and other covariates.

One way analysis of variance and $t$ tests were calculated by SPSSX procedures and $\chi^{2}$ statistics were generated by crosstabs procedures of SPSSX. Multivariate regression models were identified using backward selection in the SPSSX regression procedure. Logistic regression models were tested using CATMOD procedure in SAS.

\section{Results}

Table 1 shows the age distribution of the examined workers. The mean age was $50 \cdot 0$ (SD 12.1). As shown in the table, over half of the examined workers were 50 or older and only a small number $(5 \%)$ were younger than 30 years of age.

The duration of employment of the examined ironworkers showed a trend similar to that of the age distribution. Most workers $(62.3 \%)$ had been employed in the trade for 20 years or longer and only $14.4 \%$ gave a history of having worked in the trade for less than 10 years. One hundred and ninety eight ironworkers $(22.8 \%)$ had worked between 10 and 20 years in the trade. Thus the majority of the ironworkers $(85 \%)$ had been employed in the trade for 10 years or longer. The mean duration of employment for the group was 22.9 (SD 10.3) years and the mean latency period from first employment was $25 \cdot 7$ (SD $11 \cdot 6)$ years.

\section{OCCUPATIONAL HISTORY}

Review of lifetime work history was an important component of the interview preceding the examination. Specific questions were asked regarding work locations and type of work that the subject had performed as an ironworker. Figure 1 summarises the information obtained. It is of interest to note that $92 \%$ of the examined workers reported having worked directly with asbestos containing materials at some point in their career, indicating that potential for exposure to airborne dust containing asbestos is

Table 1 Age distribution of 869 ironworkers

\begin{tabular}{ll}
\hline Age $(y)$ & No of workers $(\%)$ \\
\hline$<30$ & $46(5 \cdot 3)$ \\
$30-49$ & $372(42 \cdot 8)$ \\
$\geqslant 50$ & $451(51 \cdot 9)$ \\
Total & $869(100 \cdot 0)$ \\
\hline
\end{tabular}




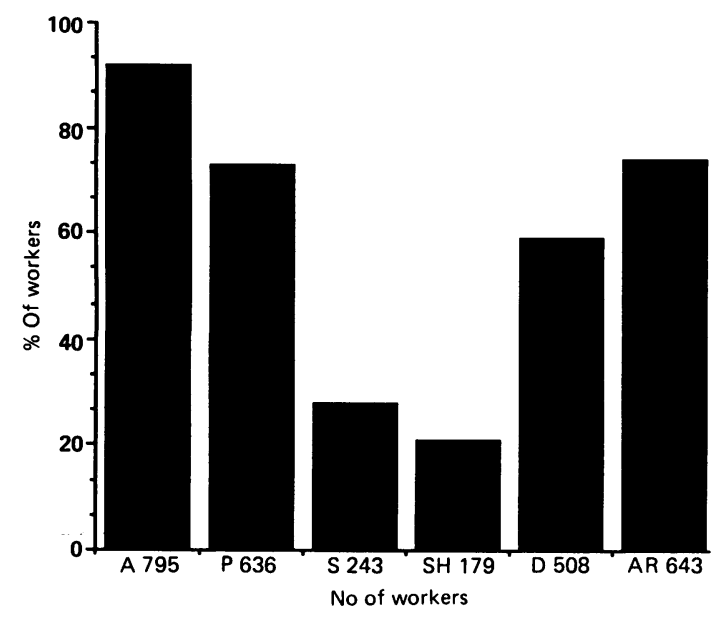

Figure 1 Selected work sites and type of work among 869 ironworkers. $A$, handled asbestos containing materials directly; $P$, powerhouse employment; $S$, shipyard work; $S H$, on board ship; $D$, demolition work; $A R$, removal of asbestos containing materials.

common among this group of ironworkers. Removal of material containing asbestos appears to be a very common mode of exposure $(74 \%)$. This procedure is often required in preparation for cutting or burning through metal pipes and conduits in demolition. Demolition work was in fact reported by 508 workers $(59 \%)$.

Employment in power facilities was also reported frequently; 636 workers $(73 \%)$ gave a positive history in this regard. Work in a shipyard, a workplace frequently associated with potential for exposure to asbestos in the past, was reported by 243 workers $(28 \%)$. Burning through paint containing lead on metal structures was mentioned by $769(89 \%)$ of the workers.

\section{CHEST RADIOGRAPHIC FINDINGS \\ Parenchyma}

Table 2 summarises the results of the chest radiographic findings with regard to parenchymal abnormalities. A profusion score of $1 / 0$ or higher was considered as an abnormal lung field.

The presence of small irregular opacities with a profusion of $1 / 0$ or above was detected in 62 workers $(7 \%)$, but only 17 of these had reading scores of $1 / 1$ or higher. The small opacities were of the irregular type, either s or $t$, and in no instance was a significant profusion of rounded opacities noted. Two hundred and eighty $(32 \%)$ of the examined workers had a profusion of $0 / 1$, representing the borderline between normal and abnormal classification in this report. Five hundred and twenty seven workers $(61 \%)$ had lung fields graded as $0 / 0$-that is, without significant increase of interstitial lung markings.
Among those with abnormal parenchyma, five had concomitant radiographic features consistent with emphysema.

Parenchymal abnormalities were associated with duration from onset of employment. Those with normal lung fields on their chest $x$ ray film had a mean duration from onset of employment of 24.9 years (SD $11 \cdot 23$ ) compared with a mean of 36.8 years (SD 10.1) for the workers with positive chest $x$ ray film readings.

\section{Pleura}

Pleural abnormalities-that is, any pleural changes (pleural thickening, diaphragmatic plaques, blunting of the costophrenic angle, or calcifications)-were often present. Three hundred and twenty nine $(38.3 \%)$ of the examined workers had positive findings in this regard. Nine workers with pleural thickening and concomitant signs of previous rib fracture on the ipsilateral side were excluded from all analyses concerned with evaluation of pleural abnormalities thought to be related to asbestos. Of these nine workers, two had a latency period of less than 20 years since first employment and seven workers had a latency period since first employment of over 20 years.

Bilateral (17.0\%) and unilateral pleural thickening $(16.8 \%)$ occurred with similar frequencies. Calcified diaphragmatic plaques were noted in $86(9.9 \%)$ of the workers.

Blunting of the costophrenic angle was recorded for 65 workers $(7 \cdot 6 \%)$. Of these, 25 had bilateral pleural abnormalities and 26 had unilateral thickening of the pleura. In only 14 cases did the pleural thickening directly concern the costophrenic angle (which we defined as diffuse pleural thickening). Thus, in most cases, pleural thickening manifested itself as circumscribed thickening (pleural plaque). The prevalence of pleural abnormalities was similar for structural and ornamental ironworkers $(35.5 \%$ bilateral and $38.8 \%$ unilateral).

The mean age of the workers with pleural abnormalities was 57.8 years (SD $10 \cdot 1$ ), and of those without pleural abnormalities $45 \cdot 2$ years (SD 10.7). Pleural thickening was also related to duration from first employment in the trade. The 531 workers with

Table 2 Profusion of small opacities of 869 ironworkers according to the ILO international classification of radiographs of pneumoconioses 1980

\begin{tabular}{lc}
\hline Profusion & No of workers $(\%)$ \\
\hline $0 / 0$ & $527(60 \cdot 6)$ \\
$0 / 1$ & $280(32 \cdot 2)$ \\
$1 / 0$ & $45(5 \cdot 3)$ \\
$1 / 1$ & $14(1 \cdot 6)$ \\
$1 / 2$ & $1(0 \cdot 1)$ \\
$2 / 3$ & $1(0 \cdot 1)$ \\
$3 / 2$ & $1(0 \cdot 1)$ \\
Total & $869(100 \cdot 00)$ \\
\hline
\end{tabular}




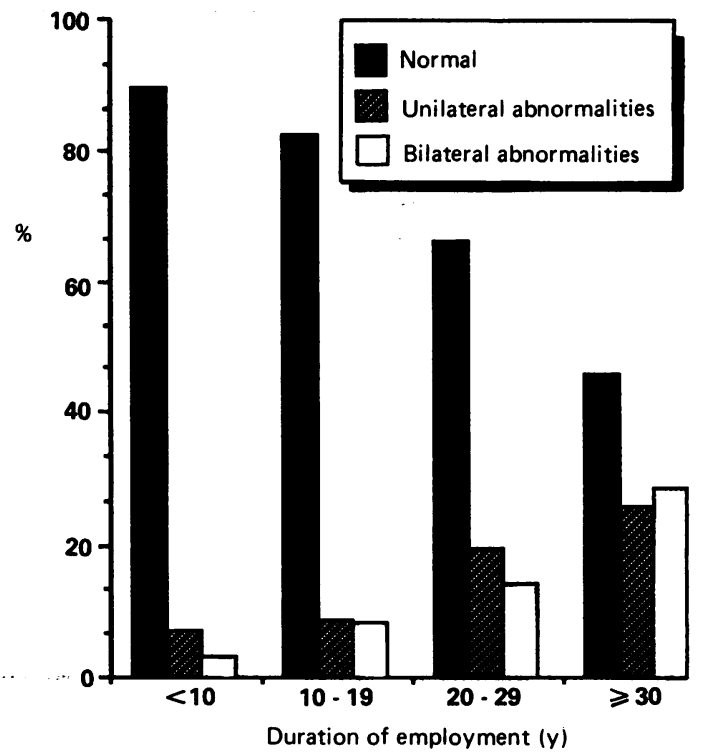

Figure 2 Pleural findings in relation to duration of employment among ironworkers.

normal pleura had a mean duration from first employment of 21.6 years (SD 10.8), compared with a mean of 32.3 years (SD 9.9) since first employment for those with abnormal pleural findings.

Among the $\mathbf{5 8 7}$ ironworkers for whom 20 years or longer had elapsed since their initial employment, $298(50.8 \%)$ showed pleural abnormalities on their chest radiographs. The prevalence of pleural changes increased to $70.3 \%$ among the 155 workers who began their employment more than 35 years ago. By contrast, only $29(8.9 \%)$ of those with less than 20 years since first employment had pleural abnormalities $\left(\chi^{2} 122.6, \mathrm{p}<0.005\right)$.

The prevalence of pleural abnormalities increased for each 10 year interval of duration of employment (fig 2). It is also of interest that 144 workers had evidence of unilateral pleural thickening. In 92 cases $(63.9 \%)$, the pleural thickening was seen along the left lateral chest wall and in $52(36.1 \%)$ it was on the right side. Thus there was predilection for left sided pleural thickening in this group of workers. The prevalence of unilateral pleural thickening showed a trend similar to that of bilateral thickening and increased with duration of employment (fig 2).

Although the overall prevalence of parenchymal abnormalities was low, pleural and parenchymal abnormalities frequently occurred together. Thus among the 62 workers with parenchymal abnormalities, 53 also exhibited pleural changes; 60 of the 62 workers with parenchymal abnormalities reported having worked 20 or more years in the ironworkers' trade.
Table 3 Prevalence of pleural abnormalities by total duration of employment and smoking state among ironworkers

\begin{tabular}{lrrrrr}
\hline & \multicolumn{4}{c}{ Total years of employment } & \\
\cline { 2 - 4 } Smoking state & $<10$ & $10-19$ & $20-29$ & $\geqslant 30$ & Total \\
\hline Smoker $(\%)$ & 8.9 & 13.6 & $36 \cdot 8$ & $61 \cdot 1$ & $32 \cdot 1$ \\
Ex-smoker $(\%)$ & 12.9 & $28 \cdot 6$ & $45 \cdot 1$ & $62 \cdot 8$ & $46 \cdot 2$ \\
Non-smoker (\%) & 11.4 & 17.8 & $37 \cdot 3$ & $65 \cdot 1$ & $39 \cdot 7$ \\
\hline
\end{tabular}

\section{SMOKING HABITS}

Three hundred and two workers (35\%) were current cigarette smokers, $385(44.3 \%)$ were ex-smokers, and 176 workers $(20.3 \%)$ reported having never smoked cigarettes. The association between smoking habits and parenchymal and pleural abnormalities on chest radiographs was studied. Among the 62 workers with parenchymal abnormalities, 58 were ex-smokers or current smokers, and four had never smoked. The distribution of the smoking habits among the 53 workers with both parenchymal and pleural abnormalities differed slightly from that among workers with parenchymal disease only $\left(\chi^{2} 4.96, \mathrm{df} 2, \mathrm{p}=\right.$ 0.08).

Among the 283 workers with pleural abnormalities only and normal parenchyma, $226(79.8 \%)$ were either smokers or ex-smokers compared with 403 $(77.0 \%)$ of the 518 workers without pleural findings. When the data were analysed with the three smoking categories treated separately, the frequency of exsmokers was significantly higher among those with pleural abnormalities $\left(\chi^{2} 12 \cdot 08\right.$, df $\left.2, \mathrm{p}=0.002\right)$.

Table 3 shows the prevalence of pleural abnormalities by duration of employment strata and smoking state. The increase in prevalence noted for each duration stratum applied to all smoking categories. Although the ex-smokers had a higher prevalence of pleural abnormalities than the other smoking groups, their mean duration of employment (25.4 years) was significantly longer than that of the non-smokers $(21 \cdot 1$ years) and smokers (20.9 years).

\section{SYMPTOMS AND PHYSICAL EXAMINATION}

Shortness of breath upon exertion was reported by $366(44 \cdot 1 \%)$ of the 830 workers for whom data were available on the respiratory questionnaire. Of those who reported shortness of breath, $32(8.7 \%)$ had parenchymal abnormalities on their chest $x$ ray film and $158(43.2 \%)$ had pleural abnormalities. A higher prevalence of pleural abnormalities was found among the symptomatic workers $(43.2 \%)$ than among the non-symptomatic $(33.8 \%)$ ironworkers $\left(\chi^{2} 7 \cdot 6, p=\right.$ 0.006).

Chronic bronchitis-that is, a history of cough and sputum production for at least three months a year during two years or longer-was reported by 167 ironworkers $(19.6 \%)$. These symptoms were 
Table 4 Pulmonary function test results among ironworkers

\begin{tabular}{lccc}
\hline & $\begin{array}{l}\text { Smoker } \\
(\text { mean }(S D))\end{array}$ & $\begin{array}{l}\text { Ex-smoker } \\
(\text { mean }(S D))\end{array}$ & $\begin{array}{l}\text { Non-smoker } \\
(\text { mean }(S D))\end{array}$ \\
\hline FVC (\% predicted) $)$ & $109.5(21.0)$ & $106.9(21.4)$ & $111.0(22.2)$ \\
$\begin{array}{l}\text { FEV } 1 \text { FVC } \\
(\% \text { predicted) }\end{array}$ & $88.3(13.3)^{\star}$ & $91.5(13.3)^{\star}$ & $97.7(38.0)$ \\
$\begin{array}{l}\text { FEF }_{25-75} \\
(\% \text { predicted })\end{array}$ & $78.4(33.4)^{\star}$ & $82.5(34.9)^{\star}$ & $92.6(32.8)$ \\
\hline
\end{tabular}

${ }^{\star} \mathrm{p}<0.05$ comparing smokers with non-smokers and ex-smokers with non-smokers.

associated with the workers' smoking state. Seventy nine of these workers $(47.3 \%)$ were smokers and 69 $(41.3 \%)$ were ex-smokers. Nineteen workers $(11.4 \%)$ reported symptoms of chronic bronchitis despite a negative smoking history. The prevalences of chronic bronchitis were $26.6 \%$ for smokers and $18.0 \%$ for ex-smokers. Pleural and parenchymal abnormalities occurred with similar frequencies among those with and without chronic bronchitis.

On physical examination of the chest, end inspiratory rales were found in $93(11 \%)$ workers. Of these, $59(63.4 \%)$ had pleural abnormalities and 16 $(17 \cdot 2 \%)$ workers had positive parenchymal findings on their chest radiographs. The prevalence of pleural abnormalities was higher among those with rales $(63.4 \%)$ than among the workers without this finding $(35.3 \%)$.

\section{PULMONARY FUNCTION TESTS}

Pulmonary function testing was performed on only $527(60.6 \%)$ of the 869 workers. This was due to technical and administrative difficulties with some of the examinations. The group for which pulmonary function tests were available did not differ significantly from the total population with respect to prevalence of pleural abnormalities. Non-smokers, however, were fewer in the group that had pulmonary function tests than among the total population.

Forty workers $(7.6 \%)$ showed a decrement in forced vital capacity (FVC) indicating a restrictive pattern of impairment. Of these, $37(93 \%)$ had been employed in the trade for 20 years or longer; 25 $(62.5 \%)$ of those with abnormal FVC had pleural abnormalities compared with a prevalence of $36.6 \%$ among the ironworkers with normal FVC $\left(\chi^{2} \mathbf{9 \cdot 4}\right.$, $\mathrm{p}=0.002$ ). Of the 62 workers with parenchymal abnormalities on chest $x$ ray film, pulmonary function studies were available on 45 of these. Only four $(6 \%)$ showed a decrement in FVC. With regard to forced expiratory volume in one second $\left(\mathrm{FEV}_{1}\right) / \mathrm{FVC}$, $36.0 \%$ of the examined workers had impairment of this variable, and $47.6 \%$ had abnormal mean forced expiratory flow during the middle of the FVC $\left(\mathrm{FEF}_{25-75}\right)$.

No significant differences in mean values for $\mathrm{FVCas}$ a percentage of the predicted value (FVC\% predicted) were found for the three smoking categories.
Both obstructive variables were significantly lower, however, in the smokers and ex-smokers compared with the non-smokers (table 4). Table 5 summarises the association between pulmonary function test results and pleural findings on the chest radiographs. The ironworkers with either unilateral or bilateral pleural abnormalities (and concomitant normal parenchyma) had significantly lower FVC\% predicted than those with normal pleura. Although there was a trend towards lower values among those with pleural abnormalities for the obstructive variables as well, the differences did not reach statistical significance except for the indicator of small airways dysfunction for those with bilateral pleural abnormalities.

Those who reported shortness of breath had significantly lower mean values of $\mathrm{FEV}_{1} / \mathrm{FVC} \%$ predicted (88.8 (SD 29.3)) and $\mathrm{FEF}_{25-75} \%$ predicted (72.6 (SD 36.5)) than the non-symptomatic workers (93.5 (SD 10.7) and 90.2 (SD 32.2) respectively, $\mathrm{p}<$ 0.05 ). Chronic bronchitis and a history of employment in shipyards or on board ship were also associated with significantly lower values of $\mathrm{FVC} \%$ predicted and $\mathrm{FEV}_{1} / \mathrm{FVC} \%$ predicted.

\section{CORRELATION AND REGRESSION ANALYSES}

Table 6 shows the correlation coefficients between selected independent variables and pulmonary function tests as dependent variables. Duration of employment, pleural disease, and shortness of breath showed the highest correlation coefficients with the restrictive variable, whereas smoking state did not correlate with this parameter. By contrast, current smoking state, respiratory symptoms, and parenchymal abnormalities were correlated with obstructive dysfunction of the large airways. Table 7, which summarises the multivariate regression analysis, further shows the associations between the restrictive parameter, duration of employment, pleural abnormalities, and shortness of breath. Smoking state was closely related to the variables indicating obstruction. Small airways dysfunction appeared to be a sensitive indicator of several parameters-that is,

Table 5 Pulmonary function test results among ironworkers

\begin{tabular}{|c|c|c|c|}
\hline \multirow[b]{2}{*}{ Function } & \multicolumn{3}{|l|}{ Pleural findings } \\
\hline & $\begin{array}{l}\text { Normal } \\
(\text { mean }(S D))\end{array}$ & $\begin{array}{l}\text { Unilateral } \\
\text { disease } \dagger \\
(\text { mean }(S D))\end{array}$ & $\begin{array}{l}\text { Bilateral } \\
\text { disease } \dagger \\
(\text { mean }(S D))\end{array}$ \\
\hline $\begin{array}{l}\text { FVC (\% predicted) } \\
\text { FEV }_{1} / \text { FVC }\end{array}$ & $112 \cdot 2(20 \cdot 6)^{2}$ & $104 \cdot 3(19 \cdot 3)^{b}$ & $103 \cdot 1(24 \cdot 8)^{b}$ \\
\hline (\% predicted) & $93 \cdot 2(22 \cdot 4)$ & $91 \cdot 5(13 \cdot 7)$ & $88.9(13.9)$ \\
\hline (\% predicted) & $88 \cdot 2(32 \cdot 5)^{2}$ & $84 \cdot 2(36 \cdot 9)^{2}$ & $70 \cdot 9(35.5)^{b}$ \\
\hline
\end{tabular}

†Results for those with pleural disease and without parenchymal disease.

Across rows values with different superscripts are significantly different $(\mathrm{p}<0.05)$. 
Table 6 Correlation coefficients between parameters of smoking, employment, and disease and tests of pulmonary function

\begin{tabular}{|c|c|c|c|}
\hline Correlation coefficient & FVC (\% predicted) & $F E V_{l} / F V C$ (\% predicted) & $F E F_{25-75}(\%$ predicted $)$ \\
\hline $\begin{array}{l}\text { Smoker } \\
\text { Ex-smoker } \\
\text { Total duration of employment } \\
\text { Parenchymal disease } \\
\text { Pleural disease } \\
\text { Chronic bronchitis } \\
\text { Rales } \\
\text { Shortness of breath } \\
\text { Ship related job }\end{array}$ & $\begin{array}{l}0.008 \\
-0.057 \\
-0.21^{\star \star} \\
-0.137^{\star \star} \\
-0.215^{\star \star} \\
-0.039 \\
-0.084 \\
-0.13^{\star \star} \\
-0.008\end{array}$ & $\begin{array}{l}-0.105^{\star \star} \\
-0.002 \\
-0.044 \\
-0.141^{\star \star} \\
-0.091^{\star} \\
-0.179^{\star \star} \\
-0.037 \\
-0 \cdot 104^{\star \star} \\
-0.07\end{array}$ & $\begin{array}{l}-0.092^{\star} \\
-0.008 \\
-0 \cdot 237^{\star \star} \\
-0.229^{\star \star} \\
-0 \cdot 202^{\star \star} \\
-0 \cdot 199^{\star \star} \\
-0.036 \\
-0 \cdot 239^{\star \star} \\
-0.114^{\star \star}\end{array}$ \\
\hline
\end{tabular}

${ }^{\star} \mathrm{p}<0.05 ;{ }^{\star \star} \mathrm{p}<0.01$.

current smoking habit and respiratory symptoms as well as abnormalities on chest radiographs.

Logistic regression analysis confirmed the association between the pleural abnormalities and duration of employment in the ironworkers' trade and lack of association between smoking habit and pleural disease. When the duration of employment was categorised into those with 20-29 years of work experience and those with more than 30 years in the trade, using the workers with less than 20 years of work experience as the comparison group, the relative odds ratios (ORs) and $95 \%$ confidence intervals $(95 \% \mathrm{CIs})$ of having pleural abnormalities were $1.23(1.04-1.47)$ and $1.55(1.30-1.85)$ respectively.

With regard to the presence of parenchymal abnormalities on chest radiographs, the association with duration of employment reached borderline statistical significance $(p=0.059)$ among the workers with 30 or more years of employment (OR 1.4, 95\% CI 0.99-1.99). A history of employment in a shipyard or on board ships was a significant factor $(p=0.003)$, however, in predicting parenchymal disease (OR $1 \cdot 49,95 \%$ CI $1 \cdot 14-1 \cdot 94)$.
The presence of rales was significantly associated with duration of employment $(p=0.009)$, but not with smoking state. On the contrary, chronic bronchitis showed a significant association with current smoking $(p=0.0001)$ and ex-smoking $(p=0.0460)$ but not with duration of employment. Shortness of breath was significantly associated with both smoking state and duration of employment suggesting a less specific or multiple factor aetiology for this respiratory symptom.

\section{Discussion}

The results of this clinical survey of ironworkers show that this group of workers is at risk for excessive exposure to airborne dusts containing asbestos. This is shown by the high prevalence of radiographic abnormalities that are consistent with asbestos associated effects. It is suggested that the exposure to airborne materials containing asbestos among this group of ironworkers originated primarily from dusts generated by manipulation of asbestos containing products which are in place in buildings and on metal structures. In the past ironworkers also ran the risk of

Table 7 Regression coefficients ( $B$ ) between independent variables (category column) and dependent variables (row) by multivariate regression analysis

\begin{tabular}{|c|c|c|c|c|c|c|c|}
\hline \multirow[b]{2}{*}{ Category } & & \multicolumn{2}{|l|}{$F V C$} & \multicolumn{2}{|l|}{$F E V_{1} / F V C$} & \multicolumn{2}{|l|}{$F E F_{25-75}$} \\
\hline & & Initial model & Best model & Initial model & Best Model & Initial model & Best model \\
\hline $\begin{array}{l}\text { Smoker } \\
\text { Ex-smoker } \\
\text { Total duration of } \\
\text { employment } \\
\text { Parenchymal disease } \\
\text { Pleural disease } \\
\text { Chronic bronchitis } \\
\text { Rales } \\
\text { Shortness of breath } \\
\text { Ship related job }\end{array}$ & $\begin{array}{l}\text { B } \\
\text { p Value } \\
\text { B } \\
\text { p Value } \\
\text { B } \\
\text { p Value } \\
\text { B } \\
\text { p Value } \\
\text { B } \\
\text { p Value } \\
\text { B } \\
\text { p Value } \\
\text { B } \\
\text { p Value } \\
\text { B } \\
\text { p Value } \\
\text { B } \\
\text { p Value }\end{array}$ & $\begin{array}{l}-3 \cdot 653 \\
\text { NS } \\
-2 \cdot 775 \\
\text { NS } \\
-0.286 \\
0.0078 \\
-5 \cdot 909 \\
\text { NS } \\
-5 \cdot 950 \\
0.0074 \\
0 \cdot 324 \\
\text { NS } \\
-0.736 \\
\text { NS } \\
-3 \cdot 013 \\
\text { NS } \\
1 \cdot 743 \\
\text { NS }\end{array}$ & $\begin{array}{c}-6.319 \\
0.0034\end{array}$ & $\begin{array}{c}-7.814 \\
0.0015 \\
-4.587 \\
0.053 \\
0.038 \\
\text { NS } \\
-8.494 \\
0.015 \\
-2 \cdot 780 \\
\text { NS } \\
-8.022 \\
0.0004 \\
-0.771 \\
\text { NS } \\
-0.861 \\
\text { NS } \\
-2 \cdot 234 \\
\text { NS }\end{array}$ & $\begin{array}{c}-7.605 \\
0.0018 \\
-4.541 \\
0.053 \\
\\
\\
-9.295 \\
0.0066 \\
-2.979 \\
0.094 \\
-8.31 \\
0.0001\end{array}$ & $\begin{array}{c}-11.07 \\
0.005 \\
-4.432 \\
0.2438 \\
-0.525 \\
0.005 \\
-20.039 \\
0.0003 \\
-6.217 \\
0.047 \\
-12.101 \\
0.0008 \\
1.274 \\
\text { NS } \\
-8.584 \\
0.0036 \\
-4.047 \\
\text { NS }\end{array}$ & $\begin{array}{c}-10.966 \\
0.005 \\
-4.54 \\
0.232 \\
-0.528 \\
0.0004 \\
-20.639 \\
0.0002 \\
-6 \cdot 193 \\
0.0465 \\
-12 \cdot 161 \\
0.0007\end{array}$ \\
\hline
\end{tabular}


working in the vicinity of insulation workers who were engaged in their work at the same construction site or power facility.

Almost one third of the examined workers also gave a history of having been employed in shipyards. Thus ironworkers have frequently been at risk for exposure to asbestos as bystanders as well, and this mode of exposure may in fact be common among this population. It must be emphasised, however, that most examined workers reported having perceived work situations in which they were required to handle or to come in contact with materials containing asbestos directly. This feature appears to be common in demolition work. During previous decades, application of insulation materials containing asbestos on iron and steel structures by spraying was frequently performed in the ironworkers' work environment with subsequent risk for excessive exposure.

The principal abnormalities consisted of pleural thickening, whereas signs of interstitial lung disease were less prevalent. This is most likely a reflection of the exposure situation, which appears to have been associated with lower levels of exposure than those experienced by asbestos insulation workers. The pleural abnormalities consisted primarily of circumscribed pleural thickening and diffuse thickening was present in only 14 cases. The observations are similar to those we have made among millwright and machinery erectors who often performed their work in environments in which there is a similar risk for primarily indirect exposure to airborne materials containing asbestos.

A higher prevalence of pleural abnormalities $(47 \cdot 2 \%)$ was noted among those ironworkers who had also been employed in shipyards or on board ships compared with those who had not $(35.0 \%)$. The mean age was higher $(53.8 v 48.3$ years, $\mathrm{p}=$ 0.03 ), however, and latency period from first employment was longer (28.5 $v 24.5$ years, $\mathrm{p}=$ 0.005 ) for those with shipyard work in their history. The mean duration of employment was not different for the two groups, and the difference in prevalence of pleural abnormalities was significant only for the ex-smoking categories.

A large number of workers with unilateral pleural thickening were found, with predilection for the left side. ${ }^{6}$ The prevalence of unilateral pleural thickening followed the pattern of the bilateral thickening in terms of its association with duration of employment suggesting that the unilateral change, in this group of workers, is also an effect of exposure to asbestos and that it may reflect an early developmental stage or milder form of pleural thickening associated with asbestos.

Overall pulmonary function was comparatively well preserved in this group of workers, but associations were found between some of the pulmonary function tests and abnormalities on the chest radiographs. Pleural plaques and duration of employment in the ironworkers' trade were associated with a decline in FVC and this association remained significant after controlling for both smoking state and absence of parenchymal disease. The relatively mild degree of interstitial lung disease noted on the chest radiographs was also reflected in a low prevalence of restrictive pattern on spirometry. No statistically significant association was found between the parenchymal abnormalities and FVC. The obstructive pattern was, however, more closely related to the abnormal parenchymal findings on $x$ ray film suggesting that an underlying obstructive lung disease was functionally more significant than the mild interstitial pattern noted on the chest radiographs.

The association between lung function and pleural plaques in the absence of parenchymal abnormalities on the chest radiograph has been studied by several investigators..$^{7-12}$ No differences in routine spirometric variables were found between one group of asbestos exposed construction workers with pleural abnormalities only shown on radiography, and comparison groups consisting of non-asbestos exposed workers and asbestos exposed workers without any abnormalities on radiographs. The group with pleural abnormalities, however, showed more frequent symptoms of chronic bronchitis and productive cough, reduced expiratory flow rates $\left(\mathrm{MEF}_{50}, \mathrm{MEF}_{25}\right)$, increased closing volume, and slight reduction in the transfer factor for $\mathrm{CO}$. These changes suggested small airways dysfunction. ${ }^{13}$ In another investigation pleural plaques were associated with abnormalities of several lung function test variables including total lung capacity (TLC), residual volume (RV), and static elastic lung recoil. These findings show likely dysfunction of the lung parenchyma, which may not be detected on chest $x$ ray film. ${ }^{14}$ It is of interest to note an investigation reporting a wide spectrum of histologically identified parenchymal abnormalities, such as peribronchiolar fibrosis, alveolar fibrosis, and large scars in association with the presence of pleural plaques. ${ }^{15}$ Although radiographic findings were not reported in that study, it showed that parenchymal abnormalities may not be uncommon in the presence of pleural plaques. An investigation of the relation between restrictive lung disease and pleural thickening in a group of sheet metal workers showed a causal link, but that early parenchymal disease, diagnosed by chest $x$ ray film, bronchoalveolar lavage, and high resolution computed tomography (CT scan) of the chest may contribute to the development of restrictive lung disease among those with pleural thickening. ${ }^{16}$

The present investigation is in accord with other studies that have identified effects consistent with excessive asbestos exposure among workers em- 
ployed in building trades. ${ }^{17} 18$ In these studies pleural thickening was also the principal abnormality found on chest radiographs, and association between restrictive pattern of impairment and pleural abnormalities was reported. The contribution of cigarette smoking in causing pleural abnormalities in conjunction with exposure to asbestos was significant in one study ${ }^{17}$ and has been suggested to be an important causal factor for pleural disease in another investigation. ${ }^{19}$ Although ex-smokers appeared to have had the most severe abnormalities in our study, multivariate regression analysis showed an association between smoking habits and obstructive parameters, and restrictive parameters were significantly associated with duration of employment and pleural abnormalities. Logistic regression analysis confirmed that duration of employment in the ironworkers' trade, which is likely to be associated with higher risk for exposure to airborne asbestos containing materials, is the most important factor in predicting pleural abnormalities on chest radiographs.

Our data suggest that medical surveillance programmes that focus on the detection of abnormalities related to asbestos ought to be given high priority among this group of workers. The data also call attention to the fact that other occupations that traditionally are not readily associated with risk for exposure to asbestos may, in fact, contain exposure situations that cause such risk to become significant. ${ }^{20}$ Health promotion programmes among ironworkers should include effort aimed at stopping smoking because of the well known harmful interaction between exposure to asbestos and this habit.

The results of this survey also suggest that educational programmes for the development of guidelines in the use of appropriate industrial hygiene measures are urgently needed among this group of workers. The number of workers who have been active in this trade is large, and further evaluations are required to assess the impact of exposure to asbestos among such workers nationwide and on the international level. The results of this investigation suggest that such evaluations are warranted.

We are grateful to the members of the International Association of Bridge, Structural, and Ornamental Iron Workers Local Unions Nos 40, 361, 417 and 580 who participated in this investigation. Funding for this project has been provided by the International Association of Bridge, Structural and Ornamental Iron Workers Union and the Environmental Health Sciences Center Grant ES-00928. Raymond Corbett, treasurer, Raymond Mullett, president, Joseph Delaney, Thomas McGowan, business agent, and Charles Sheridan provided valuable assistance in the planning of this study. Mary Corsey, research assistant, skilfully coordinated the examinations. $\mathrm{Mr}$
Rupert Fuller provided valuable assistance in preparing the manuscript.

Requests for reprints to: Alf Fischbein MD, Associate Professor, Division of Environmental and Occupational Medicine, The Mount Sinai School of Medicine, One Gustave L Levy Place, New York, New York 10029, USA.

1 Mossman BT, Gee JB. Asbestos-related diseases. N Engl J Med 1989;320:1721-30.

2 Fischbein A, Leeds $M$, Solomon SJ. Lead exposure among ironworkers in New York City: a continuing occupational hazard in the 1980's. N Y State J Med 1984;84:445-8.

3 Tsang P, Chu FN, Fischbein A, Bekesi JG. Impairments in functional subsets of T-suppressor (CD8) lymphocytes, monocytes and natural killer cells among asbestos exposed workers. Clin Immunol Immunopathol 1988;47:323-32.

4 International Labour Office. Guidelines for the use of ILO international classification of radiographs of pneumoconioses. Geneva: ILO, 1980. (Occupational safety and health series No 22 (Rev. 80)).

5 Miller A, Thornton JC, Smith H Jr, Morris JF. Spirometric "abnormality" in a normal male reference population: further analysis of the 1971 Oregon Study. Am J Ind Med 1980;1: 55-68.

6 Withers BF, Ducatman AM, Yang WN. Roentgenographic evidence for predominant left-sided location of unilateral pleural plaques. Chest 1984;95:1262-4.

7 Becklake MR, Gournier-Massey G, McDonald JC, Siemiatycki $\mathrm{J}$, Rossiter CE. Lung function in relation to chest radiographic changes in Quebec asbestos workers. I. Methods, results and conclusions. Bulletin de Physio-pathologie Respiratoire 1970;6:637-59.

8 Weill $H$, Ziskind M. Waggenspack C, Rossiter CE. Lung function consequences of dust exposure in asbestos cement manufacturing plants. Arch Environ Health 1975;30:88-97.

9 Britton MG. Asbestos pleural disease. Br J Dis Chest 1982;76: $1-10$.

10 Järvholm B, Sandén A. Pleural plaques and respiratory function. Am J Ind Med 1986;10:419-26.

11 Eliasson O, Baser M. Asbestos exposure, pleural plaques and pulmonary function. Am Rev Respir Dis 1990;141:4:A244 (abstract).

12 Rosenstock L, Barnhart S, Heyer NJ, Pierson DJ, Hudson LD. The relation among pulmonary function, chest roentgenographic abnormalities and smoking status in an asbestosexposed cohort. Am Rev Respir Dis 1988;138:272-7.

13 Hedenstierna G, Alexandersson R, Kolmodin-Hedman B, Szamosi A, Tollqvist J. Pleural plaques and lung function in construction workers. Eur J Respir Dis 1981;62:111-22.

14 Fredriksson HV, Hedenstierna H, Hillerdal G, Malmberg $P$. Increased lung stiffness in persons with pleural plaques. Eur $J$ Respir Dis 1981;62:412-24.

15 Sison RF, Hruban RH, Moore GW, Kuhlman JE, Wheeler PS, Hutchins GM. Pulmonary disease associated with "asbestos" plaques. Chest 1989;4:831-5.

16 Schwartz DA, Galvin JR, Dayton CS, Stanford W, Merchant J, Hunninghake $\mathrm{GW}$. Determinants of restrictive lung function in asbestos-induced pleural fibrosis. Am Rev Respir Dis 1990;141:4:A243 (abstract).

17 Baker EL, Dagg T, Greene RE. Respiratory illness in the construction trades. I. The significance of asbestos-associated pleural disease among sheet metal workers. J Occup Med 1985;27:483-9.

18 Sprince NL, Oliver LC, McLoud T. Asbestos-related disease in plumbers and pipefitters employed in building construction. $J$ Occup Med 1985;27:771-5.

19 Weiss W, Levin R, Goodman L. Pleural plaques and cigarette smoking in asbestos workers. J Occup Med 1981;6:427-30.

20 Young I, West S, Jackson J, Cantrell P. Prevalence of asbestos related lung disease among employees in non-asbestos industries. Med J Austr 1981;1:464-7.

Accepted 12 November 1990 